\title{
A educação superior no regime militar: rupturas ou continuidades?
}

Higher education under military regime: ruptures or continuities?

Gustavo Bianch Silva*

\begin{abstract}
Resumo
O objetivo deste artigo é discutir o processo de mudança no ensino superior brasileiro no contexto do governo de João Goulart até a ditadura militar. Apesar do seu caráter progressista, a atuação política de Jango não foi eficiente na modernização do ensino superior. No governo militar, a pressão pelas reformas educacionais aumentava à medida que o reconhecimento da crise no setor ficava mais claro, o que foi evidenciado na Reforma Universitária de 1968. Diante desse cenário político de grandes mudanças, algumas questões são necessárias: no tocante à educação superior, o golpe representou uma ruptura com o governo anterior? As mudanças feitas pelos militares foram originais ou apresentaram demandas do regime anterior? Como explicar o projeto educacional consubstanciado na reforma universitária de 1968 ? Neste aspecto, a problematização levantada neste texto busca questionar até que ponto as noções conservadoras aplicadas à reforma universitária se hibridizaram com o reformismo do período anterior ao golpe.
\end{abstract}

Palavras-chave: Educação superior. Modernização. Reformas.

\begin{abstract}
This paper aims to discuss the process of change in Brazilian higher education in the context of government of João Goulart to the military dictatorship. Despite its progressive character, Jango's political activity was not efficient in the modernization of higher education. During the military government, the pressure for educational reforms increased as the recognition of the crisis in the sector was more evident, which was consolidated in the University Reform of 1968. Under this political scenario of great change, some questions are required regarding to higher education: Did the military coup represent a break with the previous government? The changes made by the military were original or presented demands of the previous regime? How to explain the educational project embodied in the 1968 university reform? In this respect, the problematization raised in this paper seeks to question the extent to which conservative notions applied the university reform were mixed with the reformist period before the military coup.
\end{abstract}

Keywords: University education. Modernization. Reforms.

\section{Introdução}

O objetivo deste artigo é discutir o processo de mudança no ensino superior brasileiro no contexto do governo de João Goulart até a ditadura militar. É inegável que o golpe de 1964 interrompeu um processo democrático que estava em curso. Na concepção de Marcos Napolitano, a despeito de todas as críticas endereçadas ao regime anterior ao golpe, Goulart conseguiu revisar a agenda política nacional no tocante à democratização da cidadania e da propriedade (NAPOLITANO, 2014).

\footnotetext{
* Doutorando em História pela Universidade Federal de Minas Gerais (UFMG).
} 
De certa forma, existia um projeto de país governado por João Goulart, com características próximas de "[...] um trabalhismo social-democrata de corte nacionalista, calcado em uma pauta genérica, mas ainda assim inovadora." (NAPOLITANO, 2014, p. 24). Nesse aspecto, entrava em cena a defesa dos interesses da economia nacional, o que incluía a melhoria da condição de vida do trabalhador, legislação protecionista e reforma agrária.

Por outro lado, havia problemas econômicos severos. A inflação crescia e o poder de compra, consequentemente, diminuía. A desigualdade social e os problemas agrários aumentavam. Porém, o maior problema residia na esfera política, conforme acentuaram Figueiredo (1993), Toledo (1997) e Ferreira (2003). Havia um verdadeiro desarranjo nas relações do poder executivo com o Congresso, de forma a inviabilizar as sonhadas reformas nos diversos setores da economia nacional. Entre a postura conciliadora do presidente e a incapacidade de negociação por parte de seus aliados e adversários, o radicalismo do golpe deflagrado pelos militares, apoiado por civis, interrompeu as possibilidades de mudanças estruturais.

Antes mesmo de Goulart no poder, estavam em jogo duas formas distintas de enxergar o ensino superior. Esse debate prossegue no tempo e perpassa a ditadura militar em um jogo de contradições. De um lado, a opção conservadora, com ênfase na educação para o mercado de trabalho; de outro lado, o desenvolvimento de uma educação no modelo nacional-desenvolvimentista, "aliando a formação científica e tecnológica com a cultura popular e alfabetização das massas" (MOREIRA, 2011, p. 303).

Dessa forma, algumas questões são necessárias: no tocante à educação superior, o golpe representou uma ruptura com o governo anterior? As mudanças efetuadas pelos militares foram originais ou apresentaram demandas do regime anterior? Como explicar o projeto educacional consubstanciado na reforma universitária de 1968 ?

Diante disso, nossa hipótese vislumbra um panorama ambíguo em relação à educação do governo de João Goulart até a ditadura. Nesse aspecto, o pragmatismo da nova ordem inaugurada com os militares representou tanto elementos que romperam com a república anterior quanto a apropriação de práticas iniciadas antes mesmo de Goulart na presidência. Para problematizar essas questões, será exposta aqui uma discussão historiográfica, que abordará os seguintes aspectos: a crise que o setor educacional brasileiro passava na década de 1960, a proposta de modernização do 
ensino anterior e posterior ao golpe militar e, enfim, a análise do "projeto" educacional da ditadura.

\section{Crise universitária}

A literatura acadêmica referente à análise do ensino superior no contexto da ditadura militar inicia-se durante o próprio regime. Diante das necessidades de mudança do sistema educacional vigente, diversos autores se empenharam no diagnóstico da educação brasileira e nos rumos tomados a partir do golpe de 1964. O legado dos governos anteriores já não satisfazia à nova realidade da urbanização, do crescimento das cidades e da maior demanda por mão de obra qualificada. Nesse aspecto, a constatação da crise universitária parecia um consenso entre os mais diferentes grupos que debatiam o assunto. Porém, as formas de pensar as vias de transformação do sistema que eram o nó górdio da questão.

Darcy Ribeiro foi um dos primeiros expoentes a pensar o sistema educacional brasileiro no contexto das mudanças decorrentes da modernização da economia. Segundo ele, existia uma verdadeira crise multifatorial, que afetava não apenas as universidades no Brasil, mas toda América Latina. Uma crise que perpassava fatores conjunturais, sociais, políticos e, sobretudo, estruturais. Certamente, diante de um mundo em franca transformação, Ribeiro (1969) percebia a exigência de reformas profundas para aumentar o acesso ao nível superior de ensino e elevar a escolaridade da população.

No entanto, Ribeiro percebeu que existiam duas medidas conflitantes para a resolução do problema. A primeira é a modernização reflexa do sistema educacional. Por meio da aproximação com as instituições superiores do mundo desenvolvido, a saída para a crise universitária seria a adoção de elementos externos à realidade brasileira para a transformação dos quadros internos. No outro modelo, chamado por Ribeiro de crescimento autônomo, a Universidade, embora inserida em uma estrutura global, opera como órgão de "[...] perpetuação das instituições sociais, enquanto atua espontaneamente. Esses dois modelos representam somente um papel ativo no esforço de superação do atraso nacional, sendo intencionalizadas suas formas de existência e de ação com este objetivo.” (RIBEIRO, 1969, p. 9).

Notadamente, a crítica de Darcy Ribeiro reside na opção de os governos brasileiros decorrentes do golpe de 1964 operacionalizarem a reforma da Universidade 
pela interiorização de práticas externas à realidade brasileira, ou seja, uma modernização reflexa. Em detrimento de uma busca por crescimento autônomo, os militares e seus aliados civis promoveram mudanças no sistema com base na atuação de consultores e técnicos americanos no Brasil. Os interesses circunscritos a essa iniciativa são dos setores estrangeiros, que objetivavam manter o país como "[...] consumidor dos frutos da industrialização alheia, não de suas sementes [...] exportadas pelos grandes centros industriais." (RIBEIRO, 1969, p. 11).

A interpretação de Darcy Ribeiro associa a opção pela influência estrangeira de um verdadeiro complexo de inferioridade da capacidade nacional de emancipação. Segundo o autor, a opção pela modernização reflexa ressalta a "[...] exaltação em relação aos povos adiantados e de ingenuidade ou de complacência diante do caráter espoliativo dos vínculos de dependência externa.” (RIBEIRO, 1969, p. 26).

Na mesma perspectiva, Bárbara Freitag faz uma interpretação do fenômeno da reforma da educação superior sob a óptica marxista. Na sua leitura, o Estado populista tentou criar, por meio das reformas de base ${ }^{1}$, a inclusão das massas em um consumo democratizado. O golpe interrompeu esse processo. Segundo Freitag, o Estado, autor da política educacional, foi compreendido em um sentido como a “[...] conjunção de aparelhos repressivos (instância da sociedade política) e aparelhos ideológicos (instância da sociedade civil), ambos atuando a seu modo como mediadores dos interesses da classe hegemônica." (FREITAG, 1978, p. 69).

Por isso, o sistema educacional tinha como significado o preenchimento de duas funções estratégicas: a reprodução da cultura e a reprodução da estrutura de classes (FREITAG, 1978, p. 18). Novamente, os interesses dos grupos hegemônicos capitalistas eram sobrepostos no que concerne à reforma do ensino superior, que deveria suprir a estrutura de mão de obra qualificada do país. Ainda para a autora,

[...] o governo militar passará a ajustar definidamente o sistema educacional aos múltiplos interesses do capitalismo brasileiro. A política educacional passará - com o auxílio do planejamento - a transformar o sistema educacional de tal maneira que ele cumpra todas as funções de reprodução necessárias à manutenção das relações de produção. (FREITAG, 1978, p. 98).

\footnotetext{
${ }^{1}$ Reformas de Base, para Ferreira, tratavam-se "[...] de um conjunto de medidas que visava a alterar as estruturas econômicas, sociais e políticas do país, permitindo um desenvolvimento econômico autônomo e o estabelecimento da justiça social." (FERREIRA, 2003, p. 351).
} 


\section{As universidades antes do golpe}

O questionamento da ruptura dos rumos educacionais no Brasil feito pela ditadura militar foi problematizado por Luiz A. Cunha. Por um lado, esse autor corrobora as palavras de Ribeiro e Freitag em relação à modernização do ensino superior e à subordinação brasileira aos interesses estrangeiros. Segundo Cunha, a reforma empreendida no sistema de ensino superior é definida no contexto do esforço de "[...] subordinação política e econômica do país, que foi responsável pela edificação da universidade no Brasil, conforme o modelo mais avançado do mundo capitalista - o norte-americano." (CUNHA, 1988, p. 11).

Cunha critica a noção de que a modernização do ensino superior teria sido causada pelo golpe militar. A modernização da educação já estava em curso desde a década de 1940, com o serviço de consultoria dos americanos para auxiliar na criação de um instituto tecnológico. A tese de Cunha é

\footnotetext{
[...] que a concepção de universidade calcada nos modelos norte-americanos não foi imposta pela USAID, com a conivência da burocracia da ditadura, mas, antes de tudo, foi buscada, desde fins da década de 40 por administradores educacionais, professores e estudantes [...]. Quando os assessores norte-americanos aqui desembarcaram, encontraram um terreno arado e adubado para semear suas ideias. (CUNHA, 1988, p. 21).
}

Antes de problematizar o modelo de desenvolvimento da educação superior, Cunha (1988) faz uma análise do momento educacional que vivia o Brasil no contexto da década de 1960. O diagnóstico dos problemas do sistema educacional não era novidade para o regime que nascia em 1964. Os governos anteriores ao golpe não conseguiram resolver as demandas levantadas por estudantes e professores.

Nesse aspecto, o autor mostra que existia uma crise de realização social do profissional diplomado. O crescimento das oportunidades de emprego não se dava no mesmo ritmo do aumento dos alunos diplomados. Segundo Cunha (1988), todo esse processo induzia um movimento estudantil voltado para a reforma do ensino superior. Não obstante, a procura por vagas nas universidades aumentava a cada ano, embora, a oferta de vagas parecia estar inerte diante dessa situação. De acordo com Cunha,

[...] o aumento do ritmo da inviabilização dos pequenos negócios, correlativo ao da intensificação do crescimento dos monopólios industriais, comerciais e financeiros, as camadas médias davam forma ainda mais nítida [...] à ideia de relacionar o futuro dos filhos à diplomação em grau superior. $\mathrm{O}$ resultado foi o crescimento ainda mais acelerado da procura pelo ensino superior. (CUNHA, 1988, p. 32). 
Dessa forma, Cunha faz uma radiografia da educação superior brasileira no período anterior ao golpe de 1964. A organização do ensino pautava-se mais pelas faculdades isoladas do que pelas universidades propriamente ditas (CUNHA, 2007). As universidades eram compostas de faculdades, as quais podiam manter autonomia jurídica e eram compostas de cátedras, cada qual correspondendo a certa área do saber. Segundo Cunha, "[...] a reunião de certas cátedras compunha a série, e a sequência destas, o curso. A cátedra tinha no professor catedrático o titular vitalício somente substituído por morte, afastamento ou aposentadoria." (CUNHA, 2007, p. 17).

Pode-se afirmar que o ensino superior era pago desde século XIX. Com o barateamento progressivo das taxas cobradas pela escola pública, a gratuidade total do ensino passou a ser realidade a partir de 1950. A solução para o fim das taxas nas instituições de ensino tomadas no governo de Goulart foi a ausência de lei ou decreto que abolissem as taxas nas escolas superiores oficiais. Elas foram sendo mantidas em seu valor nominal até que, corroídas pela inflação, já não valia a pena cobrá-las, por ínfimas que eram. Em contrapartida, cresceu a participação do Estado, principalmente da União, no financiamento dos estabelecimentos do ensino superior, sobretudo, a partir da "federalização" (CUNHA, 2007, p. 77).

\section{Governo de João Goulart: o oposto reformador dos militares?}

No governo de João Goulart, nasceu a grande oportunidade de mudança na educação superior. A votação da Lei de Diretrizes e Bases da Educação Nacional (LDB) de 1961 aparecia como uma nova chance à correção dos problemas que afetavam os sistemas de ensino. Havia uma expectativa de transformação no panorama educacional, haja vista o viés progressista do presidente Goulart e a ambição de trazer reformas para a sociedade brasileira por meio das Reformas de Base.

Os desafios eram imensos. Em seu trabalho, Cássio Silva Moreira aponta o panorama da educação no início do governo de Goulart. Segundo o autor, em setembro de 1961, quando o presidente tomou posse,

[...] o Brasil possuía uma população em torno de 70 milhões de habitantes. Entre a faixa de 15 a 69 anos, havia aproximadamente $40 \%$ de analfabetos. Em relação aos estudantes, perto de 6 milhões $(8,5 \%)$ estavam matriculados na rede de ensino primário, cerca de 900 mil $(1,2 \%)$ estavam no ensino médio, e apenas 93 mil $(0,13 \%)$ no ensino superior. Em relação a cursos de pós-graduação, o número era mais módico, cerca de dois mil alunos (0,003\%). (MOREIRA, 2011, p. 299). 
No entanto, a expansão da educação básica durante o governo de Goulart foi substancial. O autor relata que "[...] entre 1962 e 1963 aumentou o repasse de recursos para os estados e municípios para proporcionar o ensino primário a toda à população em idade escolar." (MOREIRA, 2011, p. 204). O projeto do governo contava com a construção de milhares de escolas, incremento de suas infraestruturas e aumento nos vencimentos dos professores. A escola era vista como potencial formadora de profissionais para o mercado de trabalho, sobretudo, associada à colaboração do ensino com o desenvolvimento do país. Segundo Moreira,

\begin{abstract}
Para reorientar a escola de grau médio, determinou-se a construção de 120 estabelecimentos desse gênero. Nestes seriam ministrados cursos de $2^{\mathrm{a}}, 3^{\mathrm{a}} \mathrm{e}$ $4^{a}$ séries do ciclo do nível médio, orientados no sentido da educação para o trabalho, com opção pela prática de comércio, indústria e agricultura, adaptado às condições locais. Seria incentivada, também, a adoção, pelos ginásios, de um novo espírito de educação, voltado para a relação entre a escola, a família e a comunidade, para os problemas regionais e nacionais, e os do desenvolvimento. (MOREIRA, 2011, p. 206).
\end{abstract}

Em relação ao ensino superior, Moreira aponta a interpretação do governo em formar técnicos de alto nível para o incremento da industrialização brasileira. Para isso, foram “[...] feitas uma reformulação dos currículos universitários e a duplicação de matrículas no primeiro ano dos cursos de nível superior, determinada pelo Decreto $\mathrm{n}^{\circ}$ 53.642, de 28 de fevereiro de 1964." (MOREIRA, 2011, p. 206). A veiculação de uma verba específica para a educação, nesse caso, estava prevista na LDB com a obrigatoriedade de $12 \%$ do orçamento federal investido exclusivamente no ensino (FERREIRA, 2003, p. 361). Não obstante, a necessidade de aumentar a disponibilidade de recursos para a educação era o grande desafio para os dirigentes do Estado.

Nesse aspecto, “[...] o governo obteve recursos, para 1964, que deveriam chegar a 10 milhões de dólares, obtidos, na sua maior parte, como doação de organismos internacionais e fundações ou mediante programas bilaterais de assistência." (MOREIRA, 2011, p. 207). Ou seja, a noção da ajuda externa como componente facilitador do desenvolvimento econômico não era uma exclusividade das políticas conservadoras do regime militar. Nos anos anteriores, a despeito de toda polêmica que envolvia o papel do Estado como agente da modernização, Goulart já antecipava a forma de ação do governo em relação ao financiamento externo aplicado à educação. Porém, a discussão e a votação da LDB não corresponderam às expectativas dos setores progressistas da sociedade. De acordo com Cunha, “[...] uma concessão às forças políticas direitistas enquanto o presidente procurava concentrar forças para a 
recuperação do poder dividido com o congresso." (CUNHA, 2007, p. 116). Os professores catedráticos continuavam vitalícios e com grande influência política nas instituições; e o Conselho Federal de Educação (CFE) prosseguia com total poder de interferência nas universidades, apesar da proclamada autonomia administrativa, fiscal, disciplinar e pedagógica das instituições.

Na mesma linha de pensamento, Alexandre Tavares do Nascimento Lira ressalta que a LDB representou um verdadeiro retrocesso na reforma da educação superior pois, além da manutenção do regime de cátedras, também reforçou a composição das universidades sem preocupação com a pesquisa, uma vez que se definiu a "[...] universidade como reunião sob administração comum de cinco ou mais estabelecimentos de ensino superior, integrando-se também institutos de pesquisa e aplicação e treinamento profissional.” (LIRA, 2010, p. 262).

A fundação da Universidade de Brasília, no mesmo ano da LDB, representou um modelo de instituição que simbolizou o anseio de mudanças de diversos educadores, ainda de acordo com Lira, sendo projetada para atender às críticas do meio universitário brasileiro. Isso evidencia a ambiguidade que perpassava o governo de Goulart. Enquanto a LDB representava um passo distante para a modernização das instituições, a construção da Universidade de Brasília convergia elementos modernizantes que negavam a estrutura universitária existente.

Conforme salientou Luiz A. Cunha, a Universidade de Brasília tinha organização departamental, não havia professores catedráticos e o regime de contratação era pela legislação trabalhista. Os alunos carentes recebiam bolsas de auxílio moradia e alimentação, e a participação nos órgãos colegiados era sensivelmente maior do que nas outras universidades (CUNHA, 2007). Somado a isso, outras instituições começavam a adotar o modelo empreendido em Brasília, tais como a Universidade do Brasil, a futura UFRJ, a Universidade de Minas Gerais, atual UFMG, e a Universidade do Ceará, posteriormente, UFC.

Voltando à questão da Lei de Diretrizes e Bases, os estudantes foram incisivos na crítica à nova LDB em relação ao ensino superior, tendo sido, inclusive, usado o artifício da greve para pressionar as autoridades. Diante dos debates que envolviam a transformação da educação superior, a União Nacional dos Estudantes (UNE) teve um papel fundamental.

Luiz Antônio Cunha analisa os congressos nacionais organizados pela entidade (1961,1962 e 1963). A UNE exigia do governo Goulart algumas modificações na 
legislação, principalmente concernentes à extinção da cátedra; uma legislação própria para o professor universitário, com concursos de provas e títulos; diretores das faculdades escolhidos entre os professores e maior representação estudantil nos órgãos colegiados, sobretudo, com paridade entre os representantes (CUNHA, 2007). Em complemento, Fávero (2006) adiciona que a posição do movimento estudantil consistia em combater o caráter arcaico e elitista das instituições universitárias. As questões mais relevantes foram:

\begin{abstract}
Autonomia universitária; participação dos corpos docente e discente na administração universitária, através de critério de proporcionalidade representativa; adoção do regime de trabalho em tempo integral para docentes; ampliação da oferta de vagas nas escolas públicas; flexibilidade na organização de currículos. (FÁVERO, 2006, p. 29).
\end{abstract}

Essa questão da greve estudantil no governo de João Goulart expõe a contradição entre o discurso reformista do presidente e a real política educacional implementada com a nova LDB. O caráter popular e nacionalista exigido pelos movimentos sociais contrastava com o conservadorismo na condução das reformas educacionais. Embora o presidente contasse com o apoio dos estudantes e outros grupos de esquerda tais como a Confederação Geral dos Trabalhadores (CGT) e as Ligas Camponesas, a impaciência com o governo era substituída por pressão pela radicalização das reformas (FERREIRA, 2003).

Certamente que a LDB não representava um projeto progressista e reformador, porém havia outros projetos para educação que não se transformaram totalmente em política pública. Não é objetivo deste artigo detalhar ou analisar as propostas desses grupos, porém não poderia deixar de fazer menção a instituições ${ }^{2}$ como a Sociedade Brasileira para o Progresso da Ciência (SBPC), ISEB (Instituto Superior de Estudos Brasileiros) e a própria UNE, que também formulavam críticas e planos para a educação superior e a produção e divulgação científica.

A despeito desses "outros projetos", é notório que as reivindicações não foram atendidas, exceto em iniciativas pontuais tal como a Universidade de Brasília. De acordo com Rodrigo Patto Sá Motta, poucas semanas antes do golpe, Goulart discursou

\footnotetext{
${ }^{2}$ Luiz Antônio Cunha (2007) aborda tanto a SPBC quanto o ISEB em relação à educação superior. A primeira, uma instituição voltada para a promoção da ciência na sociedade, interpretava a necessidade de reforma do ensino superior como condição primordial acabar com o caráter livresco das universidades. $\mathrm{O}$ ISEB, como organização promotora de estudos sobre o nacionalismo no Brasil, percebia a reforma universitária como necessária à busca da autonomia e o desenvolvimento econômico desassociado ao imperialismo.
} 
“[...] sobre o tema necessidade da Reforma Universitária, falando até mesmo na criação de institutos de pesquisa, no estabelecimento de ciclos básicos, em acabar com a duplicação de meios para fins idênticos e em aumentar vagas para os excedentes etc." (MOTTA, 2014, p. 69). Porém, ainda de acordo com o autor, “[...] tais intenções não chegaram a configurar uma política universitária consistente, inclusive porque o governo esvaiu suas energias nas constantes crises políticas.” (MOTTA, 2014, p. 69).

Efetivamente, o governo de João Goulart não trouxe as grandes e esperadas realizações para o ensino superior ${ }^{3}$, tendo o golpe militar de 1964 interrompido o sonho progressista de estudantes e de muitos docentes.

No entanto, a pressão sobre dos dirigentes da ditadura para a reforma universitária começou logo nos primeiros anos do regime militar. A realização da modernização do ensino superior envolvia diferentes perspectivas no que se refere à efetivação das reformas e, nos governos militares, não existia unanimidade quanto a isso. Segundo Rodrigo Patto Sá Motta, existia uma base heterogênea de poder, que ia desde um segmento extremamente conservador e alheio a qualquer alteração estrutural até grupos simpáticos à realização de reformas sociais (MOTTA, 2014). Motta ainda acentua que

[...] os diplomatas americanos pressionavam seus aliados brasileiros para a adoção de políticas modernizadoras, e sua influência marcante, sobretudo porque vinha acompanhada dos recursos e financiamentos de que o governo necessitava desesperadamente. (MOTTA, 2014, p. 65).

As primeiras iniciativas do governo referentes à educação não foram as melhores. Estudantes foram presos, professores foram expurgados (demitidos ou aposentados) e a crise política parecia não ter fim. Havia uma convicção entre os militares de que as universidades eram completamente dominadas por grupos comunistas. Em nome da segurança nacional, a "operação limpeza" foi acionada para expurgar os supostos males advindos da subversão de esquerda.

Conforme apontado anteriormente, a ruptura em relação ao governo anterior também resvalou no movimento estudantil. Em relação ao engajamento dos estudantes, toda a liberdade anteriormente vivenciada foi dissipada, sobretudo com a Lei 4.464, de 1964 - a conhecida Lei Suplicy - que buscou desmobilizar o movimento estudantil e reduzir ao máximo a politização da participação discente nas universidades. De acordo

\footnotetext{
${ }^{3}$ Para Motta, a maior realização de Goulart foi aumentar a oferta de vagas. O avanço foi 100 mil em 1961 para 140 mil em 1964 (MOTTA, 2014, p. 69).
} 
com Motta, os protestos e passeatas estudantis foram proibidos e a UNE caiu na ilegalidade. Os únicos órgãos legais de participação discente eram de âmbito local, a saber, os Diretórios Acadêmicos (DAs) e os Diretórios Centrais de Estudantes (DCEs) (MOTTA, 2014).

No entanto, houve grande acentuação do protesto estudantil nos anos 1967 e 1968. De acordo com Germano, o governo tentava administrar a crise, inclusive com a formação de grupos e comissões do executivo e legislativo para discutir a crise universitária. A votação da lei que estabeleceu a Reforma Universitária (1968) foi votada no legislativo em caráter de urgência, sobretudo porque havia necessidade de estancar a crise política (GERMANO, 1990, p. 188). Nessa perspectiva, não há como negar que o golpe militar representou a continuidade de um projeto conservador que progredia no Brasil há décadas, seja no âmbito da modernização por meio da ajuda externa, na busca da aproximação universidade-empresa ou na tentativa de reduzir a participação estudantil nas instituições de ensino. A opção modernizadora preconizada pelo Instituto de Pesquisas e Estudos Sociais ${ }^{4}$ (IPES) não era novidade, bem como a associação de instituições estrangeiras como cooperação técnica e financeira para a educação, conforme acentuado anteriormente, já funcionava no Brasil de forma esporádica nas décadas anteriores.

\section{Modernização das universidades na ditadura militar}

O modelo modernizador adotado pelos militares relaciona-se diretamente com a ajuda externa. $\mathrm{Na}$ expectativa de atrair recursos nos mais diferentes âmbitos do setor educacional, diversos acordos financeiros foram assinados, tais como os de cooperação técnica e financiamento junto à USAID (United States Agency for International Development), como o apoio de outras instituições, tais como Fundação Rockfeller, Fundação Ford, Banco Mundial e Banco Interamericano de Desenvolvimento.

O governo militar assumia, dessa forma, a necessidade de profissionalizar os quadros internos das universidades, desde a formação acadêmica dos professores, melhorias no planejamento educacional até o investimento em infraestrutura e equipamentos. Para Arapiraca, na concepção das autoridades, um dos fatores

\footnotetext{
${ }^{4}$ O trabalho de René Dreifuss (1981) sobre o IPES escancara o objetivo maior dessa organização empresarial em relação ao país. Inicialmente, sua maior finalidade consistia em derrubar o governo de João Goulart. Com a ditadura, sua ocupação maior era fornecer diretrizes e orientações na organização do Estado, sobretudo com a promoção do liberalismo.
} 
impeditivos do seu desenvolvimento era a ausência de "[...] treinamento de autoridades estaduais de educação no preparo e execução de planos estaduais de ensino" (ARAPIRACA, 1979, p. 155).

O tema do financiamento da educação era um verdadeiro desafio para os governos militares. Existia no discurso das autoridades a necessidade de investimento na educação para qualificação da mão de obra em prol do desenvolvimento do país. No entanto, a crise econômica dos primeiros anos de regime afetava a capacidade estatal de melhorar a estrutura educacional. Nesse ponto, a associação com grupos estrangeiros tornava-se estratégica, inclusive com a existência de empréstimos e investimentos de bancos, instituições públicas e privadas dos Estados Unidos.

Esse modelo de modernização educacional, segundo Francis Mary Guimarães Nogueira, tornou-se imprescindível tanto no Brasil como país em desenvolvimento quanto para as necessidades norte-americanas no contexto da Guerra Fria. O Brasil necessitava de "[...] incorporar tecnologia estrangeira para iniciar o seu passo decisivo na constituição de uma economia capitalista, através de uma modernização ancorada na urbanização e na industrialização.” (NOGUEIRA, 1998, p. 73).

É sabido que a simples transferência tecnológica geraria mais dependência econômica do país em relação às potências estrangeiras. Por isso, para Nogueira, “[...] incorporava-se a noção de que o melhor caminho para se libertar da tecnologia importada seria priorizar a educação superior, voltada para as áreas tecnológicas." (NOGUEIRA, 1998, p. 73). Certamente, a opção modernizadora da educação encontrava um ponto contraditório, à medida que, enquanto a escolarização permitia um know-how específico para produção de tecnologia nacional, a opção pela cooperação estrangeira reforçava laços de dependência com o exterior.

Isso mostra a associação entre a educação superior e o desenvolvimento do capitalismo. Para Moreira, a opção de suplantar os problemas tecnológicos da indústria nacional se daria pela educação superior, sobretudo, por aquilo nomeado pelo autor de “[...] subordinação ao know-how estrangeiro.” (MOREIRA, 2011, p. 208):

Portanto, isso implicaria gastos em divisas, resultantes do pagamento de royalties e das vinculações econômico-financeiras criadas pela necessidade de utilizar patentes de outros países. Sem embargo, caberia ao governo estimular e amparar os institutos de pesquisas, integrando a sua atividade no esforço de renovação industrial. (MOREIRA, 2011, p. 208). 
Portanto, a concepção de educação por detrás da modernização é pautada pela "teoria do capital humano". Essa noção "[...] tenta estabelecer relação direta, imediata e mesmo de subordinação da educação à produção.” (GERMANO, 1990, p. 112). A modernização propagada pela USAID e empreendida pelos militares consistia em racionalizar os custos do sistema educacional e preparar o estudante tão somente para o mercado de trabalho. Junto a isso, havia o "[...] descomprometimento com o financiamento da educação pública e gratuita, negando, na prática, o discurso de valorização da educação escolar e concorrendo decisivamente para a privatização do ensino.” (GERMANO, 1990, p. 144).

\section{A Reforma Universitária de 1968}

Além da ajuda externa, outros elementos serão aqui analisados para compreender o projeto educacional consubstanciado na Reforma Universitária de 1968 (Lei ${ }^{o}$ 5.540). De acordo com Maria de Lourdes A. Fávero, as consultorias ofertadas pelos técnicos da USAID foram essenciais para a composição da reforma juntamente como o Plano Atcon (1966) e o Relatório Meira Mattos (1968), que também ofereceram subsídios para a composição da lei que instituiu a Reforma (FÁVERO, 1991).

Tanto no Plano Atcon quanto no Relatório, a educação é encarada como fator primordial de desenvolvimento econômico e de integração nacional; papel de modeladora do futuro social; racionalização e unificação da vida social e modernização da nação, geradora de progresso (FÁVERO, 1991). A autora reforça também que a aproximação entre universidade e o meio empresarial foi citada em ambos os documentos.

O plano foi composto pelo consultor greco-americano Rudolf Atcon por encomenda do MEC. Ele percorreu 12 universidades do país. Porém o relatório não nasceu de suas impressões sobre as visitas às universidades, pois já existia desde 1958 em um trabalho publicado pela USAID. Suas principais ideias, de acordo com Fávero, incluíam a racionalização dos gastos das instituições e a oficialização da cobrança de mensalidades; a criação de um fundo assistencial para alunos carentes; a não duplicação para fins idênticos; e a organização da universidade de acordo com a empresa privada (FÁVERO, 1991).

De acordo com Luiz Antonio Cunha (1988, p. 205), para Atcon, a necessidade maior consistia em melhorar "[...] qualidade do corpo docente, a modificação dos 
currículos, a ampliação da pesquisa e a atualização do conteúdo e das matérias ensinadas". Portanto, fica evidente, ainda segundo Cunha, que parte da proposta de Atcon resultava do senso comum, pois nela havia muito do que já insistiam professores e estudantes.

A influência do Relatório Meira Mattos também foi incisiva. Em 1967-1968, com o aumento dos protestos estudantis, a crise universitária ficava exposta para a opinião pública por meio da cobertura da imprensa. Somado a isso, parte da classe média que apoiou o golpe agora se voltava contra um governo que estancava as manifestações de seus filhos com a repressão. Segundo Fávero (1991), preocupado com os protestos e a subversão no meio universitário, o coronel Meira Mattos foi convocado para criar uma comissão especial com o objetivo de "[...] emitir parecer conclusivo sobre as reivindicações e planejar e propor medidas para aplicação das diretrizes governamentais no setor estudantil.” (FÁVERO, 1991, p. 36).

Um dos pontos mais importantes do relato do coronel se refere a disciplinar os estudantes universitários. De acordo com Cunha, a causa desses protestos estudantis seria a LDB de 1961, que instituía autonomia administrativa e disciplinar das universidades bem como atribuía poderes ao Conselho Federal de Educação, poderes esses bastante grandes (CUNHA, 1988). A solução estaria em dar maior poder aos reitores. Também, foram expostas a "[...] tentativa de agilizar a burocracia, de modo a eliminar razões imediatas para o movimento de estudantes e professores [...]" (CUNHA, 1988, p. 94-95) e a sugestão de medidas para uniformizar os procedimentos de cobrança das instituições oficiais.

Após a apreciação do Plano Atcon e do Relatório Meira Mattos, o Grupo de Trabalho da Reforma Universitária formulou o projeto de reforma que foi posteriormente transformado em lei. Rodrigo Patto Sá Motta (2014, p. 106) aponta algumas diretrizes básicas que estavam contidas na Reforma, tais como Extinção das cátedras, fortalecimento das instituições centrais, aumento das verbas das reitorias, listas sêxtuplas para escolha do reitor, representação estudantil fixada em 1/5 e unificação dos vestibulares.

A forma como a comunidade universitária recebeu a Lei $\mathrm{n}^{\circ} 5.540$ foi tão ambígua quanto a própria reforma. Motta relata que até os críticos ao regime tiveram que reconhecer o mérito do governo em lançar mão de "[...] medidas de interesse da comunidade universitária, que as reivindicava há anos.” (MOTTA, 2014, p. 107). 
O legado do sistema educacional decorrente da Reforma de 1968 foi analisado por Luiz A. Cunha. Para o autor, o caráter privatista da educação ficou evidente na ditadura. Como a lei instituía a "[...] preferência pela universidade como forma própria de organização, o Conselho Federal de Educação se empenhava em propiciar a aceleração do crescimento dos estabelecimentos privados." (CUNHA, 2014, p. 362).

No afã de encontrar o máximo de eficiência com o mínimo de gastos, o crescimento das instituições privadas de ensino foi estrondoso. Esse era exatamente o maior ponto de discórdia dos opositores do regime em relação à reforma: "o ‘economicismo' e o ‘tecnicismo' [...], assim como o risco de privatização do ensino.” (MOTTA, 2014, p. 107).

Dessa forma, a reforma para o ensino superior congregou tanto elementos que modernizaram e dinamizaram o sistema universitário - extinção das cátedras, regime departamental, sistema de créditos etc. - quanto subsídios conservadores que aceleraram o crescimento das instituições particulares e a integração universidade-empresa.

\section{Ruptura ou continuidade?}

Notadamente, embora houvesse um ímpeto reformador no interior do governo de João Goulart, as disputas políticas subsumidas no âmbito da educação superior, sobretudo por meio da LDB, não resultaram totalmente em práticas progressistas. A necessidade de conciliar políticas com os diversos grupos conservadores que rivalizavam com o projeto das Reformas de Base atrapalharam, em certa medida, o andamento de políticas educacionais almejadas pelo movimento estudantil e docentes comprometidos com a renovação da universidade.

Mesmo com o presidencialismo retomado em 1963, João Goulart carecia de argumentos para negociar com um Congresso cada vez mais polarizado entre conservadores e grupos de esquerda. Para Argelina Figueiredo, Goulart “[...] vacilava entre a necessidade de consolidar o apoio parlamentar para as reformas e a necessidade de reter a liderança da ampla coalizão de esquerdas pró-reforma." (FIGUEIREDO, 1993, p. 71).

Na esfera econômica, o exemplo que temos da dificuldade em conciliar projetos distintos estava no Plano Trienal. Ainda segundo Figueiredo, os objetivos do Plano Trienal consistiam em atrair a confiança do congresso e dos credores externos, sobretudo para o reescalonamento e o financiamento da dívida externa juntamente com 
ajuda financeira, e combater a inflação sem combater o desenvolvimento com base em mudanças no aparelho bancário, fiscal e agrário (FIGUEIREDO, 1993).

$\mathrm{Na}$ ausência de unidade em torno de como fazer as reformas propostas no plano, as negociações do governo fracassaram tanto em sua base de apoio quanto com os conservadores. Consequentemente, o projeto reformador para a educação ganhava menos fôlego dentro do último governo anterior ao golpe.

Voltando para a temática da educação na ditadura, na concepção de Luiz Antônio Cunha, "[...] a ditadura não inventou a dualidade setorial pública/privada na educação, tampouco a simbiose Estado-capital na economia.” (CUNHA, 2014, p. 361). A influência do liberalismo de apoiadores do golpe como o IPES estava tão afinado com a ditadura tanto quanto o nacionalismo econômico de muitos militares. Por outro lado, “[...] o que ela fez foi intensificar essa dualidade fundante da educação brasileira e combiná-la, de modo peculiar, com os níveis de ensino, o superior e o básico." (CUNHA, 2014, p. 361). Por esse ângulo, percebe-se que o caráter modernizador empreendido pelos militares no ensino superior não foi uma invenção do regime, pois elementos discutidos e reivindicados no pré-1964 entraram na pauta das reformas na ditadura.

Para Rodrigo Patto Sá Motta (2014, p. 50), as ações dos militares eram marcadas pelo improviso. Não havia um projeto prévio propriamente dito ${ }^{5}$ tampouco o anticomunismo comum aos grupos militares era suficiente para manter a coesão no governo. Desta forma, o pragmatismo dos militares significava a apropriação de ações disponíveis no jogo político, podendo resultar em escolhas aparentemente progressistas ou claramente conservadoras. Segundo Motta,

Os programas do regime militar resultaram das negociações e dos conflitos entre os grupos apoiadores do regime, que foram influenciados por pressões internacionais, pelo contexto econômico, pelas ações dos opositores e também pelas tradições do país, sem esquecer que as preferências pessoais dos detentores do poder igualmente entram em conta. (MOTTA, 2014, p. 50).

Nessa perspectiva, em alguns aspectos, os militares conseguiram ir além do que foi feito em parte do período histórico anterior, principalmente com referência à LDB. Muitas demandas trazidas pelo movimento estudantil foram traduzidas pelos governos,

\footnotetext{
${ }^{5}$ Enquanto Motta rechaça um projeto propriamente militar para a educação brasileira, Cunha (1988) aponta que esse projeto realmente existiu. Os golpistas tinham um projeto para a educação, elaborado pelo IPES. Não foi baixada uma lei instantaneamente para reformar a educação porque ela já estava parcialmente implementada. Só era necessário antes, atacar o ímpeto dos opositores para acelerar o processo (CUNHA, 1988, p. 20).
} 
obviamente, não como resposta aos anseios dos estudantes, mas pela conveniência suscitada no contexto da época, até porque os grupos de trabalho e de elaboração do anteprojeto da reforma universitária não contaram com a participação dos estudantes.

O próprio modelo educacional empreendido na Universidade de Brasília também foi apropriado, de certa maneira, na reforma dos militares. Cunha acentua que "[...] boa parte da concepção da 'universidade crítica', expressão que sintetizava o projeto contrário ao do governo autoritário, tinha com ele grandes pontos de convergência." (CUNHA, 1988, p. 19).

De forma geral, como pontuou Lira, a lei que aprovou a Reforma Universitária em 1968 aboliu as cátedras; instituiu o regime de tempo integral e dedicação exclusiva dos professores; o sistema departamental passou a vigorar em todas as instituições juntamente com o sistema de créditos; a periodicidade adotada foi a semestral e, por fim, o vestibular como eliminatório (LIRA, 2010). A reforma garantiu também a autonomia universitária. Todas essas demandas estavam dentro das reivindicações do movimento estudantil e também faziam parte da retórica reformista de Goulart para o ensino superior, inclusive naquele discurso citado anteriormente, pouco antes do golpe.

Portanto, analisar as políticas públicas aplicadas ao ensino superior no contexto da ditadura requer uma problematização do dualismo ruptura versus continuidade. Como explicar que o governo de Goulart com toda sua proposta de nacionalização da economia foi beneficiário do financiamento externo de instituições americanas? $\mathrm{Ou}$ como pensar em continuidade quando demandas de estudantes são apropriadas quando preteridos na construção do processo legislativo? Para Motta, “[...] o grande paradoxo da ditadura era expressar, simultaneamente, impulsos conservadores e modernizadores que, por vezes, geraram ações contraditórias.” (MOTTA, 2014, p. 51).

Não é demais reforçar que, embora o regime militar tenha adaptado demandas do movimento estudantil e outros grupos progressistas, o processo de adoção de medidas reformadoras foi extremamente arbitrário. Nos primeiros anos do governo, centenas de professores foram afastados de seus cargos e estudantes acabaram expulsos das universidades. O movimento estudantil foi controlado, a UNE extinta e as instituições de ensino superior, vigiadas. Esse modelo autoritário foi ampliado com o conhecido quinto Ato Institucional (AI-5), que promoveu novos expurgos nas universidades, o que afetou completamente o cotidiano nas instituições com a saída de muitos cientistas para o exterior e o consequente prejuízo na condução das pesquisas. 


\section{Considerações finais}

O processo de reforma do ensino superior brasileiro foi repleto de debates e embates. O país se urbanizava e novas necessidades quanto ao mercado de trabalho e à industrialização impulsionavam a juventude em direção às universidades. A grande concorrência do vestibular, a carência de vagas, a falta de estrutura, a insuficiência de docentes e a quase ausência de pós-graduação marcavam uma grande contradição entre um país em desenvolvimento e uma educação superior aquém das necessidades desse crescimento.

Não há como negar os problemas óbvios enfrentados por professores e estudantes após a entrada dos militares no poder. Embora o projeto de setores progressistas do governo Goulart não tenha sido vitorioso, existia maior atuação política e intelectual no seio das instituições superiores. A ditadura promoveu expurgos aos professores, perseguiu estudantes que pertenciam aos movimentos estudantis e interferiu diretamente na autonomia universitária. Nesse aspecto, sim, houve uma grande ruptura com o regime político proveniente de 1964. Porém o "projeto" modernizador desenvolvido pelos militares e consubstanciado na reforma universitária de 1968 foi gestado antes mesmo do golpe. A proximidade com instituições internacionais que fomentaram diversas universidades e projetos de pesquisa, a noção de racionalização dos gastos com o dispêndio mínimo de recursos, o aumento do vertiginoso das instituições privadas, o financiamento público no ensino privado, a educação superior como privilégio de classe, os pagamentos de mensalidades e/ou anuidades nas instituições públicas, a despolitização do movimento estudantil e o pragmatismo na formação (ênfase na técnica em detrimento da produção científica ou humanista) foram elementos que convergiram na política educacional dos governos militares.

Somados a isso, aspectos como extinção das cátedras, regime departamental, sistema de créditos, vestibular unificado, concurso público para os docentes, enfim, diversas demandas reivindicadas no início da década de 1960 foram colocadas em prática na lei n. 5.540. Por outro lado, esse processo escancara o caráter ambíguo da política educacional militar: a conciliação de políticas modernizadoras e conservadoras. Consequentemente, as mudanças promovidas pelos militares não foram originais. $\mathrm{O}$ "diferencial" estava no aumento daquilo que Luiz A. Cunha chamou de simbiose Estado/capital e, concomitantemente, na vigilância e controle sobre as universidades. 


\section{REFERÊNCIAS}

ARAPIRACA, José Oliveira. A USAID e a educação brasileira: um estudo a partir de uma abordagem crítica do capital humano. Rio de Janeiro: IESAE/FGV, 1979.

CUNHA, Luiz Antonio. A universidade reformanda. Rio de Janeiro: Ed. Francisco Alves, 1988.

CUNHA, Luiz Antonio. A universidade crítica: o ensino superior na república populista. 2. ed. São Paulo: Unesp, 2007.

CUNHA, Luiz Antonio. O legado da ditadura para a educação brasileira. Educação \& Sociedade, Campinas, v. 35, n. 127, p. 357-377, abr.-jun. 2014.

DREIFUSS, René. 1964: a conquista do Estado (ação política, poder e golpe de classe). Petrópolis: Vozes, 1981.

FÁVERO, Maria de Lourdes de Albuquerque. A Universidade no Brasil: das origens à Reforma Universitária de 1968. Educar, Curitiba, n. 28, p. 17-36, 2006.

FÁVERO, Maria de Lourdes de Albuquerque. Da universidade "modernizada" à universidade disciplinada: Atcon e Meira Mattos. São Paulo: Cortês, 1991.

FERREIRA, Jorge. O governo Goulart e o golpe civil-militar de 1964. In: e FERREIRA, Ferreira, DELGADO, Lucilia de Almeida Neves (Org.). O tempo da experiência democrática: da democratização de 1945 ao golpe civil-militar de 1964. Rio de Janeiro: Civilização Brasileira, 2003. p. 343-404.

FIGUEIREDO, Argelina Cheibub. Democracia ou reformas? Alternativas democráticas à crise política 1961-1964. São Paulo: Paz e Terra, 1993.

FREITAG, Barbara. Escola, Estado e Sociedade. São Paulo: EDART, 1977.

GERMANO, José Willington. Estado militar e educação no Brasil, estudo sobre política educacional (1964-1985): um estudo sobre política educacional. 1990. $444 \mathrm{f}$. Tese (Doutorado em Educação) - Universidade Estadual de Campinas, Programa de Pós-graduação em Educação, Campinas, 1990.

LIRA, Alexandre Tavares do Nascimento. A legislação da educação no Brasil durante a ditadura militar (1964-1985): um espaço de disputas. 2010. 367f. Tese (Doutorado em História) - Universidade Federal Fluminense, Instituto de Ciência Humanas e Filosofia, Programa de Pós-graduação em História, Niterói, 2010.

MOTTA, Rodrigo Patto Sá. As universidades e o regime militar: cultura política brasileira e modernização autoritária. Rio de Janeiro: Zahar, 2014.

MOREIRA, Cássio Silva. O projeto de nação do governo João Goulart: o plano trienal e as reformas de base (1961-1964). 2011. 404f. Dissertação (Mestrado em Economia) - Universidade Federal do Rio Grande do Sul, Programa de Pós-graduação em Economia, Porto Alegre, 2010. 
NAPOLITANO, Marcos. 1964: História do Regime Militar Brasileiro. São Paulo: Ed. Contexto, 2014.

NOGUEIRA, Francis Maris Guimarães. A Ajuda Externa para a Educação Brasileira na produção do "mito" do desenvolvimento: da USAID ao BIRD. Campinas, 1998. 194 f. Tese (Doutorado em Educação) - Universidade Estadual de Campinas, Programa de Pós-graduação em Educação, Campinas, 1998.

RIBEIRO, Darcy. A Universidade Necessária. São Paulo: Editora Paz e Terra, 1969.

TOLEDO, Caio Navarro de. Visões críticas do golpe. Campinas: Editora da Unicamp, 1997. 